Original

\title{
In vitro evaluation of the antimicrobial activity of a new resin- based endodontic sealer against endodontic pathogens
}

\author{
Yoshiyuki Yasuda $^{1)}$, Arihide Kamaguchi ${ }^{2)}$ and Takashi Saito ${ }^{1)}$ \\ ${ }^{1)}$ Division of Clinical Cariology and Endodontology, Department of Oral Rehabilitation, School of Dentistry, \\ Health Sciences University of Hokkaido, Ishikari-Tobetsu, Japan \\ ${ }^{2}$ Division of Microbiology, Department of Oral Biology, School of Dentistry, \\ Health Sciences University of Hokkaido, Ishikari-Tobetsu, Japan
}

(Received 13 March and accepted 8 July 2008)

\begin{abstract}
The purpose of this study was to compare the antimicrobial activities of a new resin-based SuperBond (SB) Sealer and five other sealers/cements against endodontic pathogens. The antimicrobial activities of SB Sealer, Sealapex, AH plus, Roeko Seal Automix, Canals N, and ProRoot mineral trioxide aggregate (MTA) were examined using a double-layered method. The microorganisms Staphylococcus aureus, Enterococcus faecalis, Candida albicans, Streptococcus mutans, and Streptococcus sanguinis were used. Live microorganisms were stained using triphenyltetrazolium chloride, and the zones of inhibition of microorganism growth were measured. The antimicrobial activity of SB Sealer was significantly lower than that of the other sealers, except for Pro Root MTA, against $S$. aureus, $C$. albicans, $S$. mutans, and $S$. sanguinis, but no activity against $E$. faecalis was detected. On the other hand, AH plus exhibited the highest antimicrobial activity. Pro Root MTA showed no antimicrobial activity against any of the microorganisms tested. SB Sealer offered no antimicrobial advantage over the other sealers tested except for Pro Root MTA. (J. Oral Sci. 50, 309-313, 2008)
\end{abstract}

Correspondence to Dr. Yoshiyuki Yasuda, Division of Clinical Cariology and Endodontology, Department of Oral Rehabilitation, School of Dentistry, Health Sciences University of Hokkaido, 1757 Kanazawa, Ishikari-Tobetsu, Hokkaido, 061-0293 Japan Tel: +81-133-23-2841

Fax: +81-133-23-1423

E-mail: yasuda@hoku-iryo-u.ac.jp
Keywords: SuperBond Sealer; antimicrobial activity; root canal sealer; microorganisms; Enterococcus faecalis.

\section{Introduction}

One important goal of endodontic therapy is to remove bacteria from root canals and thus prevent further infection $(1,2)$. However, it has been reported that bacteria remain in root canals even after root canal preparation using a reamer or a file and final irrigation with $\mathrm{NaOCl}$ and EDTA (3). This is probably because some bacteria survive in the dental tubules and apical rami due to their complicated anatomical structures (4). Formaldehyde and phenol agents are used for sterilization, but it is difficult to completely sterilize the root canal (5). Root canal filling is performed using gutta-percha and sealers. Filling the spaces between the gutta-percha and the root canal wall is important for preventing reinfection (6). To suppress the growth of residual bacteria, antimicrobial agents have therefore been added to the sealers (7).

Root canal-filling sealers with calcium hydroxide-, epoxy resin-, or zinc oxide eugenol-based components are clinically applied. Grossman et al. proposed that the best sealers should have good biocompatibility, good sealing ability, safety, and antimicrobial activity (8). However, no sealers satisfying these characteristics have yet been developed. Many studies have examined the antimicrobial activity of sealers, and it has been reported that paraformaldehyde, eugenol, and thymol have such antimicrobial actions (9-11). Sealapex becomes strongly alkaline due to discharged hydroxide ions, thus exhibiting antimicrobial activity $(12,13)$. 
SuperBond (SB), a 4-META/MMA-TBB resin cement, is widely used for adhesion of orthodontic brackets and the fixation of mobile teeth (14). Recently, SB Sealer with high adhesiveness has been developed. SB has been reported to have almost no cytotoxicity to dental pulp cells (15), although its antimicrobial activity remains unclear. Facultative anaerobic microorganisms such as Enterococcus faecalis, Staphylococcus aureus and Candida albicans are considered to have the highest resistance in the oral cavity, with the potential to cause failure of root canal treatment (16). Therefore the present study was performed to compare the antimicrobial activities of a new resin-based SB Sealer and five other sealers/cements against various endodontic pathogens.

\section{Materials and Methods}

The sealers tested in this study were SuperBond (SB) Sealer (Sun Medical, Shiga, Japan), Sealapex (Sybron Kerr, Romulus, MI, USA), AH plus (Dentsply DeTrey, Konstanz, Germany), Roeko Seal Automix (Coltene/Whaledent, Germany), Canals N (Showa Yakuhin Kako, Tokyo, Japan), and ProRoot mineral trioxide aggregate (MTA) (Dentsply, Johnson City, TN, USA). The compositions of the sealers are shown in Table 1. The $\mathrm{pH}$ of Pro Root MTA in $3 \mathrm{~h}$ was measured with a $\mathrm{pH}$ meter (Horiba Instruments Ltd., Kyoto, Japan) using a temperature-compensated electrode.

These materials were evaluated in triplicate for antimicrobial activity using the double-layered method as described previously $(12,13)$. The base layer comprised $10.0 \mathrm{ml}$ of sterilized Brain Heart Infusion (BHI) agar (Difco, Detroit, MI, USA) poured into $20 \mathrm{~mm} \times 100 \mathrm{~mm}$ sterilized Petri dishes. Six wells (diameter $7 \mathrm{~mm}$, depth 2 $\mathrm{mm}$ ) were made by removal of agar at equidistant points, and these were filled immediately with sealers after being mixed according to the manufacturer's instructions. The strains used for analysis were Staphylococcus aureus ATCC 25923, Enterococcus faecalis ATCC 10541, Candida albicans ATCC 10231, Streptococcus mutans Ingbritt, and Streptococcus sanguinis ATCC 10556.

The microorganisms were maintained on $\mathrm{BHI}$ agar at $4^{\circ} \mathrm{C}$. A few colonies were picked from the BHI agar, and then inoculated into BHI broth. All microorganisms were grown at $37^{\circ} \mathrm{C}$ for $24 \mathrm{~h}$ and then seeded into $15.0 \mathrm{ml}$ of the $\mathrm{BHI}$ agar to produce a turbidity of 0.5 on the McFarland scale, which corresponds to a concentration of $10^{8}$ colonyforming units per $\mathrm{ml}$. The seeded agar was added over the plate immediately after insertion of the sealers. The plates were maintained at room temperature for $2 \mathrm{~h}$ for prediffusion of the materials, and then incubated at $37^{\circ} \mathrm{C}$ for $24 \mathrm{~h}$. Aliquots of $5.0 \mathrm{ml}$ of triphenyltetrazolium chloride (TTC, Sigma) gel prepared with 1.0\% BHI agar and $0.05 \%$ of TTC were added for optimization $(12,13)$. After solidification, they were incubated at $37^{\circ} \mathrm{C}$ for $30 \mathrm{~min}$. The same procedure was conducted using a plate without the sealers (negative control). The diameter of the zone was measured as the inhibition zone $(\mathrm{mm})$ with a millimeter ruler to an accuracy of $0.5 \mathrm{~mm}$. The data are expressed as the mean $\pm \mathrm{SD}$. The data were compared using one-way analysis of variance (ANOVA) followed by Tukey's test at a level of significance of $5 \%(P<0.05)$. The different letters indicate significant differences between the sealers.

\section{Results}

To examine the antimicrobial activities of the six sealers/cement (SB Sealer, Sealapex, AH plus, Roeko seal Automix, Canals N, and ProRoot MTA) against endodontic pathogens, the diameters of the inhibition zones were measured by the double-layered method. $0.05 \%$ TCC was added to the media so that live microorganisms were dyed

Table 1 Composition of the materials tested for antimicrobial activity

\begin{tabular}{lll}
\hline Materials & Manufacturer & Composition \\
\hline SB Sealer & Sun Medical & MMA, 4-META, pulverized PMMA, tri-n-butylborane derivative \\
Sealapex & Sybron Kerr & Calcium oxide, Barium sulphate, Silica, Titanium dioxide, Zinc stearate \\
AH plus & Dentsply Detrey & $\begin{array}{l}\text { Diepoxide, Calcium tungstate, Zirconium oxide, Aerosil, Pigment, } \\
\text { 1-adamantane amine, } \\
\text { N,N'-dibenzyl-5-oxa-nonandiamine-1,9, TCD-diamine }\end{array}$ \\
Roeko Seal & Coltene/Whaledent & $\begin{array}{l}\text { Polydimethylsiloxane, Silicone oil, Paraffin-based oil, } \\
\text { Hexachloroplatinic acid, Zirconium dioxide }\end{array}$ \\
Canals N & Showa Yakuhin & $\begin{array}{l}\text { Zinc oxide, Barium sulfate, Rosin, Bismuth, Fatty acid, Propylene glycol } \\
\text { Tricalcium silicate, Tricalcium aluminate, Tricalcium oxidate, Silicate } \\
\text { oxide, Bismuth }\end{array}$ \\
\hline
\end{tabular}

MMA: methyl methacrylate

4-META: 4-methacryloxyethyl trimellitate anhydride

PMMA: poly(methyl methacrylate) 
red, and the unstained area was defined as the inhibition zone (Fig. 1). The antimicrobial activity of SB Sealer was significantly lower than that of the other sealers except for Pro Root MTA against $S$. aureus, $C$. albicans, $S$. mutans, and $S$. sanguinis, but no activity against $E$. faecalis was detected (Table 2). Among the sealers, AH plus showed the highest antimicrobial activity against $C$. albicans and $S$. mutans. Canals $\mathrm{N}$ showed high antimicrobial activity against $S$. aureus and $S$. sanguinis, comparable to that of AH plus. Sealapex and Roeko Seal Automix exhibited mild antimicrobial activities against all of the bacteria. No antimicrobial activity of Pro Root MTA against any of the bacteria was detected. The $\mathrm{pH}$ of Pro Root MTA was 11.5 in $3 \mathrm{~h}$. Among the bacteria, E. faecalis showed the highest resistance against the sealers.

\section{Discussion}

The antimicrobial activity of the sealers we tested, except for Pro Root MTA, was detected by the doublelayered method. Since live microorganisms alone were stained red by addition of $0.05 \%$ TTC to the agar media, areas with component diffusion alone and dead bacteria could be distinguished. Previous reports have suggested that there is a relationship between antimicrobial activity and size of the inhibition zone. However, expression of the inhibition zone is influenced by several factors (12). Furthermore, there is a possibility that antimicrobial substances are produced when components of sealers come into contact with plate media.

Any microorganism remaining in a root canal has the potential to cause treatment failure. The presence of $E$. faecalis, $S$. aureus, and C. albicans in root canals has been reported in therapy-resistant periapical periodontitis (16). E. faecalis is the most drug-resistant of these bacteria, and can survive in root canals for 12 months even under nutrient-deprived conditions $(6,17)$. Therefore, sealers are required to have antimicrobial activity in addition to sealing ability and biocompatibility. In this study, the antimicrobial activity of sealers against endodontic pathogens which are almost universally present in the human oral cavity was examined. We found that E. faecalis was the bacterium most resistant to all of the sealers, in agreement with the previous study (12).

Currently, root canal sealers consisting of various components are used clinically. Many studies have reported the antimicrobial activities of such sealers, but the results have not always been concordant (9-11). This is because

\section{E. faecalis}

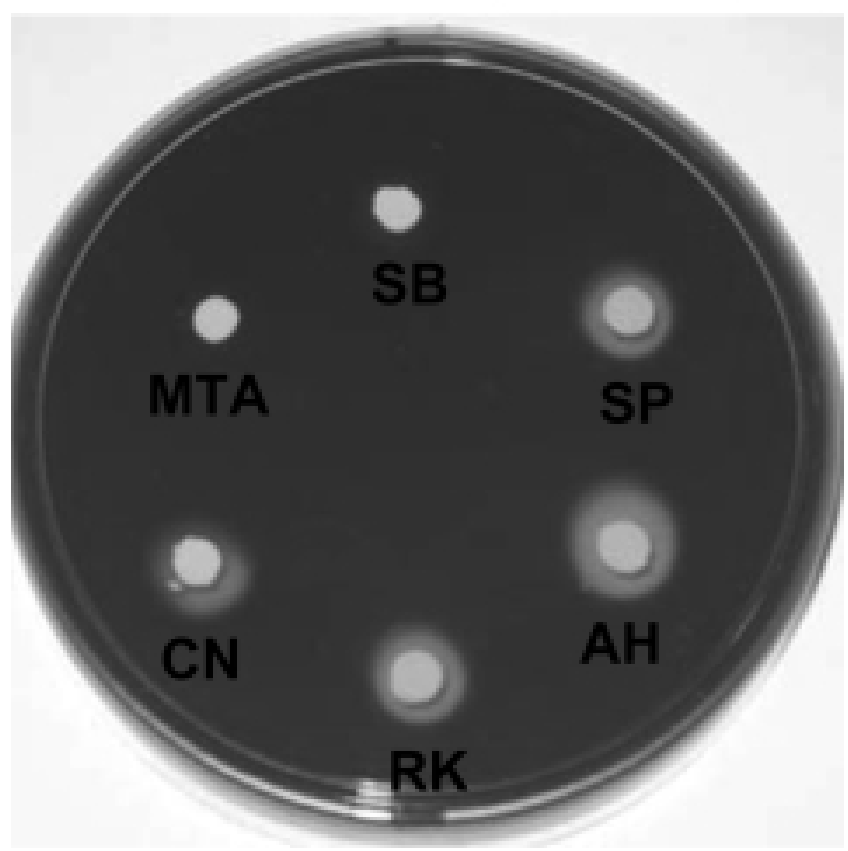

Fig. 1 Representative inhibition zones of Enterococcus faecalis determined by the double-layered method. SB: Superbond Sealer, SP: Sealapex, AH: AH plus, RK: Roeko Seal Automix, CN: Canals N, MTA: ProRoot MTA.

Table 2 Comparison of in vitro antimicrobial activity of six endodontic sealers/cements

\begin{tabular}{lccccc}
\hline Sealer & \multicolumn{5}{c}{ Pathogens } \\
\cline { 2 - 6 } & S. aureus & E. faecalis & C. albicans & S. mutans & S. sanguinis \\
\hline SB Sealer & $8.17 \pm 0.76^{\mathrm{c}}$ & 0 & $7.50 \pm 0.50^{\mathrm{c}}$ & $7.67 \pm 0.29^{\mathrm{c}}$ & $7.50 \pm 0.50^{\mathrm{c}}$ \\
Sealapex & $11.33 \pm 0.76^{\mathrm{b}}$ & $10.67 \pm 0.76^{\mathrm{a}}$ & $12.17 \pm 1.76^{\mathrm{b}}$ & $11.00 \pm 0.56^{\mathrm{b}}$ & $11.83 \pm 1.04^{\mathrm{b}}$ \\
AH plus & $16.00 \pm 1.50^{\mathrm{a}}$ & $12.33 \pm 1.53^{\mathrm{a}}$ & $16.67 \pm 1.26^{\mathrm{a}}$ & $13.67 \pm 1.04^{\mathrm{a}}$ & $16.83 \pm 0.29^{\mathrm{a}}$ \\
Roeko Seal & $10.67 \pm 1.26^{\mathrm{b}}$ & $10.00 \pm 0.50^{\mathrm{a}}$ & $11.00 \pm 0.50^{\mathrm{b}}$ & $10.67 \pm 0.29^{\mathrm{b}}$ & $12.17 \pm 0.29^{\mathrm{b}}$ \\
Canals N & $14.50 \pm 1.00^{\mathrm{a}}$ & $11.33 \pm 1.04^{\mathrm{a}}$ & $11.50 \pm 0.50^{\mathrm{b}}$ & $11.50 \pm 0.87^{\mathrm{b}}$ & $16.33 \pm 0.58^{\mathrm{a}}$ \\
ProRoot MTA & 0 & 0 & 0 & 0 & 0 \\
\hline
\end{tabular}

The data are expressed as means $\pm \mathrm{SD}$ of the inhibition zones $(\mathrm{mm})$ determined by the double-layered method. The data were compared using one-way analysis of variance (ANOVA) followed by Tukey's test at a level of significance of $5 \%(P<0.05)$. The different letters indicate significant differences between sealers. 
variations in the concentrations of both agar and the tested bacteria, the amount and hardening time of the sealers, the incubation time, and evaluation methods employed affect the outcome of the agar diffusion test. It has been reported that eugenol, which is continuously eluted from zinc oxide eugenol-based sealers such as Canals, induces a strong inflammatory reaction $(18,19)$. Therefore, Canals $\mathrm{N}$ with the same components as Canals, excluding eugenol, was used in the present study for examination of antimicrobial activity. This sealer showed the second highest antimicrobial activity, suggesting that zinc oxide may be involved in this effect. Some studies of AH26, which is an epoxy resinbased sealer, have reported that formaldehyde eluted from it has strong antimicrobial activity and cytotoxicity, and that another component, bisphenol A diglycidylether, is mutagenic $(20,21)$. AH plus, which has recently been improved by its manufacturer, showed the strongest antimicrobial activity among the sealers tested. Since AH26 has been reported to discharge almost no formaldehyde (22), other components such as epoxy resin and amines must therefore be responsible for the strong antimicrobial activity of AH plus. Sealapex, which is a calcium hydroxide-based sealer, has been well studied, because it accelerates the closure of apical foramina (23). A high $\mathrm{pH}$ due to hydroxide ions discharged from Sealapex is unfavorable for bacteria, and their growth is therefore suppressed (24). This sealer showed mild antimicrobial activity, but its strong alkalinity could damage the surrounding tissues. MTA contains calcium oxide, which forms calcium hydroxide on contact with water (25-27). It has been reported that this cement has antimicrobial activity similar to that of calcium hydroxide-based sealers (25), and that its activity against $C$. albicans is particularly strong $(28,29)$. However, MTA showed no antimicrobial activity against any of the microorganisms tested in this study. Although Torabinejad et al. observed that the $\mathrm{pH}$ of MTA was 12.5 in $3 \mathrm{~h}$ (25), that of Pro Root MTA was 11.5 in the present study. Considering that microorganisms cannot grow above $\mathrm{pH} 12, \mathrm{pH}$ is considered to be one of the reasons for the conflicting results. However, previous reports have also suggested that there is little difference in antimicrobial activity between MTA and Pro Root MTA (29). Therefore, further investigations are needed to clarify the mechanism responsible for the antimicrobial activity of these cements.

Conventional sealers are used only for filling the spaces between the gutta-percha and the root canal wall. On the other hand, SB Sealer has strong adhesiveness and high sealing ability due to the formation of resin tags and hybrid layers in the dental tubules (14). Although it is ideal for sealers to exert antimicrobial activity while maintaining their adhesiveness, the present study revealed that SB Sealer has only low antimicrobial activity. Since a previous study demonstrated that both bacterial penetration into dentin and caries spread were significantly reduced by sealing with a resin composite (30), SB Sealer with a high degree of adhesiveness is considered to be useful as a sealer. In conclusion, SB Sealer showed the second lowest antimicrobial activity among the sealers/cements tested in this study.

\section{Acknowledgments}

This work was supported by Grants-in-Aid (Nos. 18659563 and 18791407) from the Japan Society for the Promotion of Science, and by a Grant from the Research Center, Health Sciences University of Hokkaido. The authors wish to express special thanks to Toru Kawamorita (Divisiton of Clinical Cariology and Endodontology, Department of Oral Rehabilitation, School of Dentistry, Health Sciences University of Hokkaido) for his technical assistance in the microbiology component of this study.

\section{References}

1. Kiryu T, Hoshino E, Iwaku M (1994) Bacteria invading periapical cementum. J Endod 20, 169-172

2. Sen BH, Piskin B, Demirci T (1995) Observation of bacteria and fungi in infected root canals and dentinal tubules by SEM. Endod Dent Traumatol 11, 6-9

3. Jeansonne MJ, White RR (1994) A comparison of $2.0 \%$ chlorhexidine gluconate and $5.25 \%$ sodium hypochlorite as antimicrobial endodontic irrigants. J Endod 20, 276-278

4. Byström A, Sundqvist G (1981) Bacteriologic evaluation of the efficacy of mechanical root canal instrumentation in endodotic therapy. Scand J Dent Res 89, 321-328

5. Zehnder M (2006) Root canal irrigants. J Endod 32, 389-398

6. Sedgley CM, Lennan SL, Appelbe OK (2005) Survival of Enterococcus faecalis in root canals ex vivo. Int Endod J 38, 735-742

7. Grossman L (1980) Antimicrobial effect of root canal cements. J Endod 6, 594-597

8. Grossman LI, Oliet S, Del Rio CE (1988) Endodontic practice, 11th ed, Lea \& Febiger, Philadelphia, 242

9. Siqueira JF Jr, Gonçalves RB (1996) Antibacterial activities of root canal sealers against selected anaerobic bacteria. J Endod 22, 79-80

10. Abdulkader A, Duguid R, Saunders EM (1996) The antimicrobial activity of endodontic sealers to anaerobic bacteria. Int Endod J 29, 280-283 
11. Mickel AK, Nguyen TH, Chogle S (2003) Antimicrobial activity of endodontic sealers on Enterococcus faecalis. J Endod 29, 257-258

12. Leonardo MR, da Silva LA, Tonomaru Filho M, Bonifácio KC, Ito IY (2000) In vitro evaluation of antimicrobial activity of sealers and pastes used in endodontics. J Endod 26, 391-394

13. Sipert CR, Hussne RP, Nishiyama CK, Torres SA (2005) In vitro antimicrobial activity of Fill Canal, Sealapex, Mineral Trioxide Aggregate, Portland cement and EndoRez. Int Endod J 38, 539-543

14. Kawasaki M, Hayakawa T, Takizawa T, Sirirungrojying S, Saitoh K, Kasai K (2003) Assessing the performance of a methyl methacrylatebased resin cement with self-etching primer for bonding orthodontic brackets. Angle Orthod 73, 702-709

15. Fujisawa S, Atsumi T (2004) Cytotoxicities of a 4META/MMA-TBBO resin against human pulp fibroblasts. Dent Mater J 23, 106-108

16. Peciuliene V, Reynaud AH, Balciuniene I, Haapasalo M (2001) Isolation of yeasts and enteric bacteria in root-filled teeth with chronic apical periodontitis. Int Endod J 34, 429-434

17. Portenier I, Haapasalo H, Ørstavik D, Yamauchi M, Haapasalo M (2002) Inactivation of the antibacterial activity of iodine potassium iodide and chlorhexidine digluconate against Enterococcus faecalis by dentin, dentin matrix, type-I collagen, and heat-killed microbial whole cells. J Endod 28, 634-637

18. Lindqvist L, Otteskog P (1980) Eugenol: liberation from dental materials and effect on human diploid fbroblast cells. Scand J Dent Res 88, 552-556

19. Gulati N, Chandra S, Aggarwal PK Jaiswal JN, Singh M (1991) Cytotoxicity of eugenol in sealer containing zinc-oxide. Endod Dent Traumatol 7, 181185

20. Kayaoglu G, Erten H, Alaçam T, Ørstavik D (2005) Short-term antibacterial activity of root canal sealers towards Enterococcus faecalis. Int Endod J 38, 483488
21. Tai KW, Huang FM, Huang MS, Chang YC (2002) Assessment of the genotoxicity of resin and zincoxide eugenol-based root canal sealers using an in vitro mammalian test system. J Biomed Mater Res 59, 73-77

22. Cohen BI, Pagnillo MK, Musikant BL, Deutsch AS (1998) Formaldehyde evaluation from endodontic materials. Oral Heath 88, 37-39

23. Holland R, de Souza V (1985) Ability of a new calcium hydroxide root canal filling material to induce hard tissue formation. J Endod 11, 535-543

24. da Silva LA, Leonardo MR, da Silva RS, Assed S, Guimarães LF (1997) Calcium hydroxide root canal sealers: evaluation of $\mathrm{pH}$, calcium ion concentration and conductivity. Int Endod J 30, 205-209

25. Torabinejad M, Hong CU, McDonald F, Pitt Ford TR (1995) Physical and chemical properties of a new root-end filling material. J Endod 21, 349-353

26. Al-Hezaimi K, Al-Shalan TA, Naghshbandi J, Oglesby S, Simon JH, Rotstein I (2006) Antibacterial effect of two mineral trioxide aggregate (MTA) preparations against Enterococcus faecalis and Streptococcus sanguis in vitro. J Endod 32, 10531056

27. Holland R, de Souza V, Nery MJ, Faraco Júnior IM, Bernabé PF, Otoboni Filho JA, Dezan Júnior E (2001) Reaction of rat connective tissue to implanted dentin tube filled with mineral trioxide aggregate, Portland cement or calcium hydroxide. Braz Dent J 12, 3-8

28. Al-Nazhan S, Al-Judai A (2003) Evaluation of antifungal activity of mineral trioxide aggregate. $\mathrm{J}$ Endod 29, 826-827

29. Tanomaru-Filho M, Tanomaru JM, Barros DB, Watanabe E, Ito IY (2007) In vitro antimicrobial activity of endodontic sealers, MTA-based cements and Portland cement. J Oral Sci 49, 41-45

30. Shimada Y, Kawashima M, Higashi T, Foxton RM, Tagami J (2004) Histologic evaluation of adhesive restorations on dentin caries in rat molar teeth. Quintessence Int 35, 200-205 